\title{
Negotiation of Narratives in Postmodern Picture Book
}

\author{
Shuxuan $\mathrm{Wu}$ \\ English Department, Qingdao University of Science and Technology, Qingdao, China
}

\begin{abstract}
The past couple of decades see the emergency and flourish of postmodern picture book, which gives more freedom and power to the reader. Therefore, the postmodern picture book has proved to be a fruitful field of study for inquiries into the narrative potential of the fixed image. This paper explores the complex narratives in postmodern picture book with a case study of White and Black. It is hoped to shed some lights on this issue.
\end{abstract}

Index Terms-postmodernism, picture book, narrative

\section{POSTMOdernism}

Our world is made of many peoples, cultures, and stories that happen simultaneously. Today's technology, with its possibilities of instant worldwide communication, has brought this knowledge of pluralistic narratives to the forefront. Postmodernism emphasizes the interconnectedness of world cultures and the tolerance needed to embrace the resulting, possibly conflicting, views (Fehr, 1997). Postmodernism flows from popular art (Stevenson, 1994). Postmodern art, because it recognizes and places value on multiple narratives, embraces multiculturalism. This postmodern multiculturalism looks at art production within "the context of its culture of origin" (Efland, Freedman, \& Stuhr, (1996, p. 13). Postmodern art also recognizes and calls attention to social conditions (Efland, Freedman, \& Stuhr, 1996, p. 35). Postmodernism has turned upside down the long-held views of the superiority of originality, of the avant-garde, and of the judgments of art critics. It has given the art world new perspectives and multiple viewpoints: "Appropriation, collage, and juxtaposition of meanings are in" (Clark, 1996, p. 2). In this new postmodern art world, even the ideas of copying and using coloring books are accepted. These items are seen as tools for what they can teach and for what usefulness they can hold (Clark, 1996). Postmodernism has become a part of our culture, including children's literature. Children and adults alike enjoy reading and looking at postmodern picture books.

\section{POSTMOdern Picture Book}

Postmodern picture books go out of their way to ask "What is real? The story? The page? The book itself?" (Goldstone, 2002, p. 364). This is contrary to how traditional storybooks try to suspend reality and draw the reader into their fictional world. Certain characteristics are found in postmodern picture books. While not every postmodern picture book will have all of these characteristics, often these books: 1) Do not follow a linear pattern; 2) Are self-referential; 3) Have a cynical or sarcastic tone; 4) Require the reader to make sense or meaning of the book-the reader can choose which parts to use or not use; 5) Have gaps or ambiguities in the story; 6) Are playful-may have jokes, puns or irony; 6) Have shifting viewpoints; 7) Have multiple narratives; 8) Have jokes in the illustrations that are not present in the text (Goldstone, 2002, p. 363).

Intertextuality is a common post- modem picture book device. This is when a book takes two or more familiar texts and intertwines them to create a new story. A variation is to juxtapose two disparate stories to meld them into a new narrative.

Only in the last 25 years have these postmodern picture books developed (Goldstone, 2002). As a practical matter, the idea of the text and pictures juxtaposed or falling off the page could not have been produced just a few years ago. The same technology that allows newspapers to routinely print color pictures has made the printing process flexible enough to produce these books.

Postmodern picture books are polysemic-that is, they have or are characterized by many meanings. These books cause the reader's attention to move from place to place, from text to picture and back, in a fluid way (Mackey \& McClay, 2000). Sidebars filled with additional information also slow the reader down. It is the reader's choice to explore and read this additional information or not. In this way, postmodern picture books are much like computer hypertext or television channel surfing (Goldstone, 2002).

Picture books that are written from the feminist, social concern or "other- culture" perspective are also considered to be postmodern, because the issues of feminism and multiculturalism belong to our postmodern world.

A postmodern picture book that looks at a social concern is Eve Bunting's Smoky Night, which is about the Los Angeles riots. Patricia Polacco's The Keeping Quilt is an example of a book from feminist viewpoint. Allanl Say's Grandfather's Journey or Ina R. Friedman's How my Parents Learn to Eat are examples of postmodern multicultural 
picture books.

With so many narratives and viewpoints to take in, and so many details and nuances to discover, today's readers do not read postmodern picture books as much as they experience them. This active experiencing by the reader is essential to the postmodern picture book's manifold narratives. Because the reader is forced to participate in making the narratives of the postmodern picture book, these books are "fiction about making fiction," otherwise known as metafictional. Reading a postmodern picture book then becomes a lesson in narrative construction (Trites, 1994, pp. 231-232).

Adolescents especially appreciate postmodern picture books. This age group loves to "get" the inside joke (Mackey $\&$ McClay, 2000). "Many children's books wink past the child reader to the adult beyond, or wink past the adult to the child" (Stevenson, 1994, p. 33). The traditional picture book was targeted to the young reader. The postmodern picture book appeals to a much wider audience: Varying levels of reading expertise, ages, and sophistication can all enjoy such books (Anstey, 2002). It is not only the parody and pastiche of these books that has cross- generational popularity. For example, Eve Bunting's picture books, including Fly Away Home that deals with homelessness, appeal to all age categories. Postmodern art embraces all parts of a culture, including popular art. Based on critical theory, the boundaries between high and low art are considered artificial and meaningless. Seen through this lens, picture books are recognized as a viable cultural artform (Fehr, 1997).

\section{NARRATIVES IN Postmodern Picture Book}

Given the general consensus on the substantial weight of both pictorial and verbal narrative codes in the picture book, it is only logical that many studies attempt to give an overview of the different types of interaction between words and images in this surprisingly complex art form. With this purpose in mind, scholarship on the picture book has devoted considerable attention to the issue of 'irony'. According to Perry Nodelman, words and pictures can never simply repeat or parallel each other, because of the inherent differences between verbal and visual modes of communication. Images cannot explicitly assert attitudes towards the phenomena they display, for example. They can, however, visually demonstrate attitudes, while words are incapable of directly expressing emotion through shape and color. Because visual and verbal modes of communication are subject to diverging sets of constraints, the images in a picture book can never simply illustrate the words, but will necessarily offer different types of information to the reader: "As a result, the relationships between pictures and texts in picture books tend to be ironic: each speaks about matters on which the other is silent" (p. 221). Nodelman even has it that every picture book tells at least three stories: a verbal one, a visual one, and a third one that "tends to emerge from ironies created by differences between the first two" (p. 2). In keeping with the contemporary emphasis on the theatrical aspects of the picture book, the kind of irony Nodelman has in mind here is in fact synonymous to dramatic irony, for the third storyline is only accessible to the reader, who therefore has an advantage over the characters within the picture book. Readers necessarily know more than the protagonists in the verbal and/or visual stories.

Others think Nodelman's thesis about the endemic nature of irony in the picture book is overstated, and that one would do better to draw up a taxonomy that could do justice to the whole spectrum of different word-image interactions in picture books, ranging from relatively harmonious concord to blatant contradiction. Thus, Maria Nikolajeva and Carole Scott have come up with the categories of symmetrical, enhancing, complementary, counterpointing and contradictory interaction. In opposition to Nodelman's view, the first three categories allow for the possibility that words and pictures may closely cooperate in the narration of one and the same story. In symmetrical interaction, words and pictures basically repeat each other. When they enlarge each other's semantic range, we are dealing with enhancing interaction, which may culminate in complementary interaction, when words and pictures make truly independent contributions to one and the same story line. Only the last two categories coincide with Nodelman's concept of the inherently ironical picture book. In the case of counterpointing interaction, words and images generate meanings "beyond the scope of either one alone" (p. 226), which may even go as far as downright contradiction.

In this article, I would like to go deeper into the potential of word image combinations to generate stories, while contributing to the debate about irony in the picture book through a detailed analysis of David Macaulay's boundary-breaking picture book Black and White (1990).

David Macaulay knows his books are metafictional. In 1991, his book Black and White won the Caldecott medal. In his acceptance speech, Macaulay said, "The subject of the book is the book." The book even contains a warning label that it is up to the reader (not the author or the text) to construct the narrative (Trites, 1994, p. 233).

Black and White presents four different and simultaneous stories on each page. Each story is illustrated in a different stylistic manner. Are the stories connected or not? It is up to the reader to decide by deciphering any or all of the available clues. The manner and order of the reading is not prescribed (Goldstone, 2002). Interestingly, many adult readers at first balk at reading Black and White. Even though the book has few words, these readers do not like the book because it is "too hard" or "too weird." They want to be passive, but this book will not allow it (Trites, 1994).

When third-year preserves teachers were asked to read this book, they also initially disliked it. It made too many demands upon them as readers and caused considerable stress. They felt that it was confusing and intimidating (Anstey, 2002). Teachers often will not choose Black and White for their students for this reason. They seem to think that "hard is bad," while the children who delight in this postmodern intertextuality feel that "hard is fun" (Mackey \& McClay, 
2000, p. 196).

The illustration styles match the textual narratives, with four distinct visual styles gradually intermingling and blurring, then reasserting themselves. The uses of color and line are distinct in each quadrant. "Seeing Things" is depicted in misty watercolors, with the characters defined by a few brushstrokes of naturalistic, muted color. The more clearly defined pen-and-ink lines of "Problem Parents" use black, Complex Narratives in Black and White 93 browns, and white to give a sepia effect. In the two right-hand page quadrants, colors are more vibrant, with "A Waiting Game" drawn with a broad range of colors and definite contour lines. The abstract shapes of cows and people in "Udder Chaos" use solid colors with almost no shading. Visually as well as narratively, boundaries are transgressed and transformations occur. As the visual styles blur together, the book goes to black and white, with the respective color and line styles reestablished before the end of the narratives. Each quadrant transforms as well.1 The soft-focus watercolors of "Seeing Things" give way to sharply defined words on paper scraps; the visual point of view changes energetically in "Problem Parents"; the full color but static train station comes to life through the confetti of black and white newspaper in "A Waiting Game"; and the shapes in "Udder Chaos" fragment into increasingly abstract images. Needless to say, the visual elements of the book alone are worthy of a full study.

\section{TEACHING AND CHILDREN READING}

The adults often underrated children's abilities to understand, much less enjoy it. They tended to think that the book is suitable for junior high readers and older. Their reliance on reading partners for collaborative meaning making, and their conclusion that such scaffolding is beyond the reach of younger children. The assumption, stated or implicit, was that re-reading was a mark of inadequacy and that "hard is bad."Yet the young readers consistently reveal the reverse. In many cases, particularly with the grade 4 and 6 readers, their abilities to make connections across the stories arose from their attention to the visual jokes and intertextuality of the stories; their delight stemmed from their discoveries when they linked pieces of a narrative puzzle. The challenge was a large part of the fun. Re-reading was neither a chore nor a sign of inadequacy - they rightly knew that this book requires "careful inspection," as Macaulay recommends in his warning.

Jon Scieszka (1998) has suggested that adolescents are more sophisticated visual readers of his books than are adults, cueing into the visual jokes and references more attentively than their elders. Similarly, these transcripts of children and adults reading Black and White parallel his claim. Even the young children read it with intent to make meaning, and their efforts were handsomely rewarded. The wildly noisy and playful illustrations seemed to give license to young readers to play along and not worry much about interpretations; this playfulness is rewarded in rich interpretations.

Scieszka (1998) also comments on the feeling of being part of what Frank Smith (1985) has called "the literacy club" through humor and parody. Recalling his love of Mad magazine and Rocky and Bullwinkle, Scieszka notes, "You knew something funny was going on there, even if you only understood half of the jokes. But it inspired you to go find out what the rest of those jokes were, and look up things that they mentioned." Scieszka, Macaulay, and other writers who refuse to write at the lowest common denominator in humor or literary technique offer children valuable literacy lessons. Perhaps adults, with the best intentions, sometimes deprive authors of the opportunity to teach children direct and powerful reading lessons.

Dresang and McClelland (1995) note that Black and White "appeals to the resourcefulness of the reader" (p. 708). In this reading event, readers' resourcefulness was increased by the social context, which encouraged scaffolding in the construction of meaning. Just as Dresang and McClelland conclude that Macaulay's book is "greater than the sum of its parts," so, too, may teachers conclude that readers constructing a text together can be greater than the sum of the individuals. The lack of content direction for the reading event allowed readers to build interpretations by recursive, digressive pathways of their own making. One group of fourth-grade readers included a boy who almost immediately focused upon the "black-and-white" qualities and puns in the book, exclaiming while reading the red-boxed warning on the title page, "Hey! It's black and white and red-black and white and read all over!" This keen observation allowed his entire group to appreciate many of the visual jokes on their first reading, as the appearance of black and white objects on the pages does indeed help readers to make connections among the stories. As readers interpreted and discussed the book, most realized the importance of the illustrations for connecting the four stories. As Scieszka noted, adolescents tend to read the illustrations in his books more carefully than do adults, and his generalization is borne out by the readers in this study. Meek (1988) discusses adults' tendencies to make one kind of reading do for all, and that as we become more experienced in reading, we can become less skilled. Some such limitation seems to have occurred for some of the adult readers who are thoroughly grounded in a tradition of text superiority over illustrations.

In an age in which reading is increasingly rooted in multimedia forms, the implications for teachers and librarians are clear. Reading teachers and librarians who wish to promote children's reading development cannot become complacent about literacy skills gained and refined in print-based media. The need for adults to continue to learn new strategies and to re-learn old ones is essential as new forms of texts make different demands on readers of all ages. Additionally, successful teaching requires that teachers be able to appreciate and build on the depth and breadth of strategies that their students actually use. When Dresang writes of a "radical change" (1999) in the ways in which literature is presented in handheld book format, she cites Macaulay's works as exemplars of this change. Teachers and others who promote reading need to account for these changes. 
Teachers are consistently surprised to learn of other readers' preferences. In solitary reading, the reading process itself is easily taken for granted, the combination of a social situation and a text that problematizes the act of reading foregrounded the idea that the act of reading should not be taken for granted. When teachers realized that others in their groups chose to read differently, and indeed, were seriously impeded in their reading if they attempted to conform to another way of reading, they saw the implications for children in their classrooms. In the traditional text progression is left page top-to-bottom, right page top-to-bottom. Teachers, trained in graphic design, followed their attraction to the graphic style of "Udder Chaos" (bottom right quadrant), reading that quadrant first on each double page spread and then proceeding on to whichever other quadrant grabbed their eye. Teachers acknowledged somewhat ruefully that they would have discouraged a child who attempted to read the book in such order, but they also realized that their attention to the illustrations had enabled them to key in more closely to the narrative connections than they had done on their own.

\section{Reading the Positive AND NeGative Spaces}

In his acceptance speech for the Caldecott Medal, David Macaulay (1991) spoke about the need for viewers and readers to discern what appears and what is "undrawn" in texts: In picture making, that which is undrawn is referred to as 'negative space,' and it is essential to read both the positive and the negative spaces together to fully understand the image. (p. 342)

The ability to read what is not written in literature is a skill that can be developed quite young and is useful, indeed essential, in adult reading. Whether readers solve an Agatha Christie mystery (Mackey:1991), for example, or delight in the puzzles of a Jeannette Winterson novel, our successful reading depends in large part upon the ability to "read" what is unwritten as well as what is written. In Black and White and in other complex contemporary picture books, the interplay of illustrations and words provides rich experiences for young readers to develop this skill. An ability to select and hone details, to determine what should be part of the positive or negative spaces is also essential to well-crafted writing.

Meek (1988) notes that readers need to learn what not to pay attention to, such as the publishing information on the title page. Writers such as David Macaulay and Jon Scieszka make us pay attention again, signaling by breaking title page conventions, for example, their intention to call narrative conventions into question. Macaulay's warning about the four stories - or one story - tells us directly to expect ambiguity in this book. He teaches his readers how to think about his ambiguity and does not leave the teaching to an intermediary. The publishing information pages at the beginning and end of Black and White convey information essential, or at least germane, to the construction of meaning possible for readers. Meek (1988) notes that a reader's move into newer, harder books depends on a tolerance for ambiguity, an understanding that patience is needed and that the author will eventually resolve the puzzles (p. 30). This tolerance marks the difference between readers who only read the same kinds of reading material and those who move on to more varied and difficult reading.

Such tolerance for ambiguity in the comfortable form of the picture book may provide a bridge between traditional print forms and newer forms of reading, known or as yet unknown. Dresang and McClelland (1995) see Black and White as a link with hypertext, for example. Certainly, children raised with such challenging fiction may work easily in hypertext, and vice versa. They will develop the flexibility and alertness to cues, in text or illustrations at least, to attend to an author's structure. The interplay of visual and textual elements, as well as auditory ones, is a common feature of multimedia presentations. Stewig (1995) notes that evidence exists that young children attend to design features, and he suggests that teachers can profitably pay attention to layout features in teaching young children (p. 176).

Books such as Black and White teach us, in Meek's words, what readers need to know. As teachers and librarians, we can teach best by letting our young readers meet such texts in situations that allow for scaffolding learning and enjoyment, without inserting ourselves unnecessarily as intermediaries, without assuming that young people need the manual to read the book. We do well to take a lesson from their use of computers - children install the program and start to play; they don't read the manual.

\section{REFERENCES}

[1] Anstey, M. (2002). "It's not all black and white": Postmodern picture books and new literacies. Journal of Adolescent \& Adult Literacy, 45,444-457.

[2] Clark, R. (1996). Art education: Issues in postmodernist pedagogy. Reston, VA: National Art Education Association.

[3] Dresang, Eliza T. (1999). Radical Change: Books for Youth in a Digital Age. New York: The H.W. Wilson Company.

[4] Dresang, Eliza T., and McClelland, Kate. (1995). "Black and White: A journey. The Horn Book Magazine, (Nov.-Dec.), 704-710.

[5] Efland, A., Freedman, K., \& Stuhr, P. (1996). Postmodern art education: An approach to curriculum. Reston, VA: National Art Education Association.

[6] Fehr, D. E. (1997). Clutching the lectern, or shouting from the back of the hall: A comparison of modern and postmodern arts education. Arts Education Policy Review, 98, 27-31.

[7] Goldstone, B. P. (2002,). Whaz up with our books? changing picture book codes and teaching implications. Reading Teacher, 55,362-350.

[8] Mackey, M., \& McClay, J.K. (2000). Graphic routes to electronic literacy: Polysemy and picture books. Changing English: 
Studies in Reading \& Culture, 7, 191-201.

[9] Macaulay, D. (1991). "1991 Caldecott acceptance speech," Journal of Youth Services in Libraries, 340-347.

[10] Mackey, Margaret. (1991). Developing readers: Lessons from Agatha Christie. Reading, 25 (July), $25-29$.

[11] Meek, Margaret. ( 1988). How Texts Teach What Readers Learn. Stroud: The Thimble Press.

[12] Nodelman, Perry. (1988). Words About Pictures: The Narrative Art of Children's Picture Books. Athens and London: The University of Georgia Press.

[13] Nodelman, Perry. (1996). "Illustration and Picture Books," in International Encyclopedia of Children's Literature, Peter Hunt, ed., pp. 113-124. London: Routledge.

[14] Nikolajeva, Maria and Carole Scott. (2000). The Dynamics of Picture Book Communication. Children's Literature in Education, 31, 225-239.

[15] Scieszka, Jon, and Smith, Lane. (1992). The Stinky Cheese Man and Other Fairly Stupid Tales. New York: Viking/Penguin Group.

[16] Smith, Frank. (1985). Reading Without Nonsense. New York: Teachers College Press.

[17] Stewig, John W. (1995). Looking at Picture Books. Fort Atkinson, WI: Highsmith Press.

[18] Stevenson, D. (1994). "If you read this last sentence, it won't tell you anything": Postmodernism, self-referentiality, and The Stinky Cheese Man, Children's Literature Association Quarterly, 19, 32-34.

[19] Trites, R. S. (1994). Manifold narratives: Metafiction and ideology in picture books. Children's Literature in Education, 25, 225-242.

Shuxuan Wu was born in Inner Mongolia, China in 1978. She received her M.A in linguistics from Ocean University of China in 2004.

She is currently a lecturer in the School of Foreign Languages, Qingdao University of Science and Technology. Her research interests include SFL and children's literature. 